\title{
Use of Case Studies to Promote Critical Thinking in Occupational Therapy Students
}

Denise D. Allen

Florida Gulf Coast University

Susan Toth-Cohen

Thomas Jefferson University

Follow this and additional works at: https://encompass.eku.edu/jote

Part of the Curriculum and Instruction Commons, Educational Methods Commons, Health and Physical Education Commons, Occupational Therapy Commons, and the Scholarship of Teaching and Learning Commons

\section{Recommended Citation}

Allen, D. D., \& Toth-Cohen, S. (2019). Use of Case Studies to Promote Critical Thinking in Occupational Therapy Students. Journal of Occupational Therapy Education, 3 (3). https://doi.org/10.26681/jote.2019.030309

This Original Research is brought to you for free and open access by the Journals at Encompass. It has been accepted for inclusion in Journal of Occupational Therapy Education by an authorized editor of Encompass. For more information, please contact Linda.Sizemore@eku.edu. 


\title{
Use of Case Studies to Promote Critical Thinking in Occupational Therapy Students
}

\begin{abstract}
Critical thinking is a necessary component of clinical reasoning that should be addressed as part of the graduate curriculum for occupational therapists. For students to apply critical thinking in practice they must also have confidence and minimal anxiety about their abilities. Case-based learning was chosen to address critical thinking skill development, increase confidence, and decrease anxiety. The purpose of this mixed methods pilot study was to evaluate progressively independent engagement with case-based learning on student performance, confidence, and anxiety in applying critical thinking skills in the clinical setting. Critical thinking was measured using a rubric to assess students' performance in analyzing the case studies with decreasing levels of instructor guidance over the semester. Confidence and anxiety levels were measured using a Likert confidence and anxiety scale at the start and end of the semester. Qualitative data was collected through telephone interviews to determine ways in which classroom activities translated to a clinical setting and to elicit student feedback about the lesson design and what they felt they learned in class after the first Level II fieldwork. All three areas of critical thinking, confidence, and anxiety improved, demonstrating a significance of $p$
\end{abstract}

\section{Keywords}

Clinical reasoning, case-based learning, occupational therapy, confidence, anxiety

\section{Creative Commons License}

\section{(c) 1 (i) (\$)}

This work is licensed under a Creative Commons Attribution-Noncommercial-No Derivative Works 4.0 License.

\section{Acknowledgements}

The authors would like to acknowledge the students and the faculty of Florida Gulf Coast University Occupational Therapy Program for making this course design and research possible. 


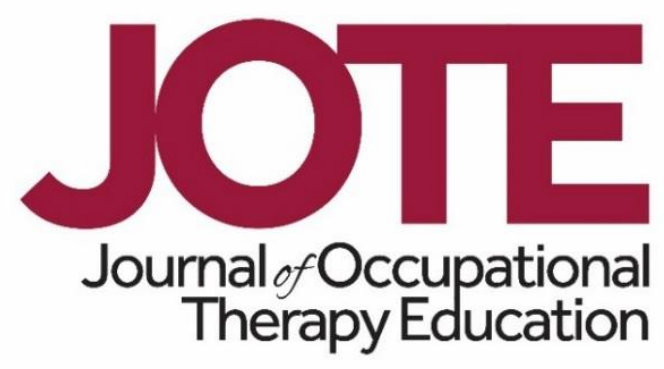

Volume 3, Issue 3

\title{
Use of Case Studies to Promote Critical Thinking
}

in Occupational Therapy Students

Denise D. Allen, OTD, OT/L, CHT ${ }^{1}$ and Susan Toth-Cohen, PhD, OTR/L²

Florida Gulf Coast University ${ }^{1}$

Thomas Jefferson University ${ }^{2}$

United States

\begin{abstract}
Critical thinking is a necessary component of clinical reasoning that should be addressed as part of the graduate curriculum for occupational therapists. For students to apply critical thinking in practice they must also have confidence and minimal anxiety about their abilities. Case-based learning was chosen to address critical thinking skill development, increase confidence, and decrease anxiety. The purpose of this mixed methods pilot study was to evaluate progressively independent engagement with casebased learning on student performance, confidence, and anxiety in applying critical thinking skills in the clinical setting. Critical thinking was measured using a rubric to assess students' performance in analyzing the case studies with decreasing levels of instructor guidance over the semester. Confidence and anxiety levels were measured using a Likert confidence and anxiety scale at the start and end of the semester. Qualitative data was collected through telephone interviews to determine ways in which classroom activities translated to a clinical setting and to elicit student feedback about the lesson design and what they felt they learned in class after the first Level II fieldwork. All three areas of critical thinking, confidence, and anxiety improved, demonstrating a significance of $p<0.001$. Overall, results of this pilot study suggest that case studies using the format of progressively independent engagement may help improve critical thinking and confidence and reduce anxiety. Also, although limited by the small number of participants, the qualitative content analysis indicated that students found the case studies helpful to develop and apply critical thinking to their fieldwork experiences.
\end{abstract}




\section{INTRODUCTION}

Perspectives on the role of education have moved beyond a focus on transmitting knowledge to helping students develop skills that support becoming self-directed, lifelong learners (Berkhout et al., 2015; Raidal \& Volet, 2008; Silen \& Uhlin, 2008). Critical thinking is a crucial component of becoming a lifelong learner (Hasim, Yasin, \& Rosli, 2015; Murdoch-Eaton \& Whittle, 2012). While defined in different ways, a core element of critical thinking is self-guided thinking that allows synthesizing learning to evaluate information in an informed manner with a goal of always improving thinking skills (Foundation for Critical Thinking, 2017; Lederer, 2007). Critical thinking is foundational to occupational therapists' (OT) ability to provide evidence-based, individualized services; OTs must constantly be learning and applying their skills to new situations and reflecting on their practice to assure the best course of action for their clients (American Occupational Therapy Association [AOTA], 2015b; AOTA, 2017; Szeyeng \& Hussain, 2010; Velde, Wittman, \& Vos, 2006). Thus, to better prepare students for fieldwork and the clinical setting it is important to do a better job at addressing critical thinking skills in college, and the need is well established in the OT literature (Holmes \& Scaffa, 2008; Jaffe, Gibson, D’Amico, 2015; Lederer, 2007; Neistadt, 1996; Velde et al., 2006; Vogel, Geelhoed, Grice, \& Murphy, 2009).

While case studies have been widely used to develop critical thinking, their application has produced inconclusive results that are not necessarily better than other approaches (Thistlewaite et al., 2012). However, some of the inconsistencies found in studies of critical thinking may stem from inadequate attention to lesson design. To promote learning, case study design must (a) be explicit and align with objectives (Heft \& Scharff, 2017; Lederer, 2007), (b) provide the just right challenge (Schunk, 2012), and (c) promote confidence and reduce anxiety to allow for application of learning (Fry \& MacGregor, 2014). Thus, lesson design, not just the methods used, must be considered to determine the effectiveness of a teaching tool (Heft \& Scharff, 2017).

Additionally, when designing evidence-based lessons, several factors should be considered: (a) pedagogy that supports critical thinking, (b) student skill level, and (c) student level of confidence and anxiety. Instructional methods must be aligned with sound pedagogy that allows achievement of teaching objectives (Ornstein \& Hunkins, 2013). An aim of the classroom should be helping students develop attributes associated with critical thinking and confidence to encourage becoming lifelong learners (Lederer, 2007; Raidal \& Volet, 2009). For teaching to be effective, the skills must be carried over and applied in the clinical setting. Critical thinking skills developed in the OT program must convert to clinical reasoning and lifelong learning (Otting, Zwaal, Tempelaar, \& Gijselaers, 2010). Moreover, students' beliefs about skills and confidence have been shown to greatly influence how those skills are applied in fieldwork and beyond (Fry \& MacGregor, 2014; Suliman \& Halabi, 2007; Salbach \& Jaglal, 2010). It is important to create lessons that promote confidence and reduce anxiety in addition to ensuring sound design. Knowledge alone is not enough to guarantee continued application after graduation (Thomas, Saroyan, \& Dauphinee, 2011; Salbach \& Jaglal, 2010). Thus, a pilot study was designed to examine the effect of explicit lessons on critical thinking on students' ability to apply critical thinking to clinical situations in order 
to facilitate carryover of these skills to fieldwork. The following research questions guided the inquiry: (a) can completing explicit lessons on critical thinking improve the use of critical thinking skills to facilitate carryover of these skills to the clinical setting in fieldwork, (b) does the use of progressively more independent case studies contribute to improved use of critical thinking skills, and (c) do explicit lessons on critical thinking contribute to enhanced confidence and a reduction in anxiety.

\section{LITERATURE REVIEW}

\section{Critical Thinking}

The volume of knowledge expected by healthcare professionals today is too great to expect rote memorization to be sufficient (Reed, 2014). There is a need for students to develop the competencies of applying skills autonomously to facilitate problem-solving (Khan et al., 2015). It is impossible to address every possible scenario students will encounter, so they must be able to apply learned concepts in a variety of ways in the clinical setting (Brudvig, Dirkes, Dutta, \& Rane, 2013; Kaddoura, 2011). Critical thinking is recognized as a necessary skill for OTs to address unique situations and truly be client-centered (Mitchell \& Xu, 2011).

Critical thinking involves multiple skills including (a) asking pertinent questions, (b) searching available information to inform answers to the questions, (c) examining biases, (d) analyzing and interpreting data, and (e) assessing the outcomes and adapting approach in future situations (Elder \& Paul, 2009; Mitchell \& Xu, 2011). For students to apply critical thinking skills, they must have a good foundational base of knowledge (Brudvig et al., 2013). Then students must synthesize and interpret information to provide interventions for a diverse clientele (Mitchell \& Xu, 2011). Once decisions are made, reflection occurs to determine how outcomes will influence future choices and experiences (Hofsten, Gustafsson, \& Häggström, 2010). Development of critical thinking skills can bring confidence, flexibility, creativity, and an openmindedness to clinical practice (Hong \& Yu, 2017), which can support clientcenteredness.

\section{Lesson Design: Case-based Learning}

Although experiential learning has been identified as one of the most valuable instructional methods for critical thinking that is also well-received by the students (Henderson, Coppard, \& Qi, 2017; Goldbach \& Stella, 2017), it is not always practical. An important aspect of experiential learning is the interaction with real clients. Casebased learning can also be used to create an authentic simulation to help develop critical thinking skills (Thistlewaite et al., 2012). Authenticity can be improved using client videos and cases the students are likely to see. Cased-based learning also is founded in sound pedagogy, can be varied for facilitation, and can help promote confidence and reduce anxiety (Thistlewaite et al., 2012).

Case-based learning is founded in constructivism, which focuses on the interaction between the (a) individuals, (b) environment, and (c) behaviors and is important to consider when trying to develop higher order skills such as critical thinking (Schunk, 
2012; Velde et al., 2006). The key concepts of constructivism include (a) knowledge is constructed in an incremental way based on prior learning, (b) learning is active, (c) interaction with the material should be multi-sensory, and (d) social interactions are critical (Schunk, 2012). The instructor's role is to provide guidance and facilitation based on the students' zone of proximal development: the distance between their current state of knowledge and skill and their potential levels (Schunk, 2012). Dependent on the level of skill and problem solving of the student, there needs to be guidance by the teacher/expert to promote learning versus just searching through the information (Kirschner, Sweller, \& Clark, 2006; Schunk, 2012). Different forms of case-based learning are designed to promote varying amounts of facilitation, creating the right challenge to stimulate learning (Jaffe et al., 2015; Kirschner et al., 2006; Savery, 2006; Schunk, 2012).

Case-based learning is considered active and more learner-centered instruction (Cattaneo, 2017). Active learning is considered important and avoids common problems of conventional teaching such as passive learning that discourages motivation, and reduces competency to apply learning (Chung, 2001). Active learning is thought to help develop self-directed learning and the ability to apply knowledge to address new problems that could be encountered in the clinic (Chung, 2001). Case-based learning is founded on the idea of reasoning through a case and applying the information to different contexts (Cattaneo, 2017). Previous knowledge is applied, results are learned, and new learning helps adapt prior knowledge and changes how future information might be viewed. This process is similar to how clinical expertise is created and developed over time. Case-based learning is considered an effective approach because it can allow links to be made between pieces of knowledge in a scaffolded way. Failure, which is a necessary part of learning, is also not penalized as it is in other forms of teaching (Cattaneo, 2017). Using cases can also develop a student's willingness to learn and solve practical problems (Qi, Yi, Mo, Huang, \& Yang, 2018). Although the literature has shown mixed results of case-based learning, it is in part due to the wide variety of ways in which lessons are designed (Thistlethwaite et al., 2012).

\section{Student Considerations}

A well-developed lesson may not facilitate learning if it causes too much anxiety and stress (Goswami, 2008). The brain prioritizes emotional responses over other stimulus, so aversive emotional responses to the situation will block learning (Friedlander et al., 2011; Goswami, 2008; Schunk, 2012). Although there may be some personal, external stresses individual students are facing that cannot be addressed, creating a positive learning atmosphere will enhance the lesson objectives (Friedlander et al., 2011). Also, learning is restricted when there is fear of punishment versus reward (Goswami, 2008), so it is important to consider how assignments are assessed and encourage expression of ideas when working through possible solutions of case studies. Allowing students to interact in groups can promote testing of ideas in a more comfortable arena than direct interaction with the instructor, reducing possible emotional turmoil (Moffett \& Fleisher, 2013). Creating an environment that promotes positive interaction may also help students reduce anxiety and gain confidence. 
Reflection can also be incorporated into case studies lessons, which allows for more integration of experience and critical reflection needed beyond direct application from class to fieldwork (Bhoyrub, Hurley, Neilson, Ramsay, \& Smith, 2010; Blaschke, 2012; Taylor, 2008). Deeper reflection facilitates student learning by allowing a more individualized perception of the materials (Bhoyrub et al., 2010). This is important as students leave the educational system and must make clinical decisions independently and support their beliefs when collaborating with other health professionals (Blaschke, 2012).

\section{METHODS}

\section{Research Design}

The research was a mixed method design to evaluate the effect of progressively independent engagement with case-based learning on student performance, confidence, and anxiety in applying critical thinking skills in the clinical setting. During class, quantitative data was gathered to assess changes in critical thinking, confidence, and anxiety from the start to the end of the semester. Qualitative data was collected through telephone interviews conducted after completion of the first Level II fieldwork. Data was used to explore ways in which classroom activities translated to a clinical setting and to elicit student feedback about the lesson design and perceived learning.

The design was approved by the university's Institutional Research Board. Consent of the students was gathered at the end of the didactic semester by a neutral instructor not involved in the course. Students were reminded of their ability to withdraw when request for volunteers for the phone interview was sent via e-mail one month prior to the end of their first Level II fieldwork and again two weeks prior to the planned phone interview times scheduled at the end of their first Level II fieldwork.

\section{Participants}

A convenience sample of 32 masters level OT students all enrolled in their last didactic semester was used. All students enrolled in the class were eligible for the study. Consent was gained from 31 of the 32 students to use their data. Eighty-one percent $(n=25)$ of participants were female, and $77 \%(n=24)$ were Caucasian. Minority ethnicities represented a higher percentage compared to national statistics of OT students (AOTA, 2015a) with 13\% ( $n=4)$ identifying as Hispanic, and $3 \%(n=1)$ as American Indian. Eighty-four percent $(n=26)$ of the students were 22 to 26 years old, with $16 \%(n=5)$ aged from 29 to 48 . The phone interviews had five volunteers, three females and two males of whom three were Caucasian, one Hispanic, and one American Indian.

\section{Instruments}

Three instruments were used to complete this project: (a) a critical thinking rubric used to grade the case studies, (b) the Nursing Anxiety and Self-Confidence with Clinical Decision Making Scale (NASC-CDM ${ }^{\circledR}$; White, 2011), and (c) phone interview questions. A critical thinking rubric that showed good validity and reliability was chosen for this project (Hildenbrand \& Schultz, 2012). The rubric assessed seven areas of critical 
thinking including summarizing the problem, identifying quality evidence, integrating a variety of perspectives, and identifying implications. Each area could be scored from one to six with three categories of emerging, developing, and mastering (Hildenbrand \& Schultz, 2012).

To assess confidence and anxiety levels a modified version of the NASC-CDM ${ }^{\circledR}$ (White, 2011) was used with permission and minor modifications. The NASC-CDM ${ }^{\circledR}$ was developed to determine confidence and anxiety levels in relation to the clinical decisionmaking process (White, 2011, 2013). The survey consisted of 27 questions asking for student perception of confidence and anxiety in three dimensions of clinical decision making: (a) using resources to gather information and listen fully, (b) using information to see the big picture, and (c) knowing and acting (White, 2011). Questions used a sixpoint Likert scale ranging from "not at all" to "totally" to ask about confidence and anxiety for each question. Norming or standardization had not been established. Construct validity was established with a high measure of internal consistency for both self-confidence and anxiety. Convergent validity of $\geq 0.50$ was established against the General Self-Efficacy scale with the confidence measure but was less for the anxiety measure. The scale met the rating of 0.70 , which is considered acceptable for a new measure for reliability (White, 2011). Modifications included minor word changes including switching the word "nursing" for "OT" and modifying "during shift change report" to "from other team members".

Standardized phone interview questions were developed to explore students' perceptions of the ways in which the case study lessons applied to their fieldwork experience. Standardized questions are best suited for a mixed method design with specific research questions (Arsel, 2017). Questions included looking at the (a) perceptions of the case study format used in class, (b) what they learned about critical thinking through the case studies, (c) student confidence in applying skills, and (d) how they applied knowledge of critical thinking to fieldwork experiences. The interviewer also asked any follow-up questions for clarification or deeper exploration of a topic touched on by the initial answers. Table 1 provides examples of the phone interview questions utilized.

Table 1

Phone Interview Questions

1. Thinking about the case studies presented in upper extremity class, how did this process prepare you for your real-world experiences?

2. Please describe how the flow of case studies helped or hindered your learning.

3. How do you think the case studies help/hindered application of critical thinking skills on fieldwork?

4. What effect did working through the case studies \& receiving feedback have on your confidence/anxiety about fieldwork? 
5. What elements of critical thinking skills do you think are important/not important for clinical practice?

6. What examples can you give of using critical thinking skills on your fieldwork?

\section{Procedures}

This study was designed to be completed during the students last didactic semester before starting Level II fieldwork (Figure 1). Students were given the pre-test case study the first week of class. After the case study they completed the confidence and anxiety survey using Checkbox. The students were all given a copy of Guide to Critical Thinking (Elder \& Paul, 2009) and asked to read the guide and watch a flipped lecture on critical thinking prior to the first intervention case study. The critical thinking process was reviewed in class and students were told prior to each case study to use these materials and that the goal of each case study was to promote critical thinking. The intervention case studies were created in alignment with videos from the ICE Learning Center (https://www.icelearningcenter.com/). Diagnoses for the case studies were chosen based on common diagnoses found in practice and included a wrist fracture, rotator cuff injury, and cerebral vascular accident (CVA) with left affect. The case studies were completed within a week after focus in class on these diagnoses. All intervention case studies were completed in groups of four students.

The first intervention case study asked ten questions to guide students through important questions to guide writing an assessment and developing a treatment plan

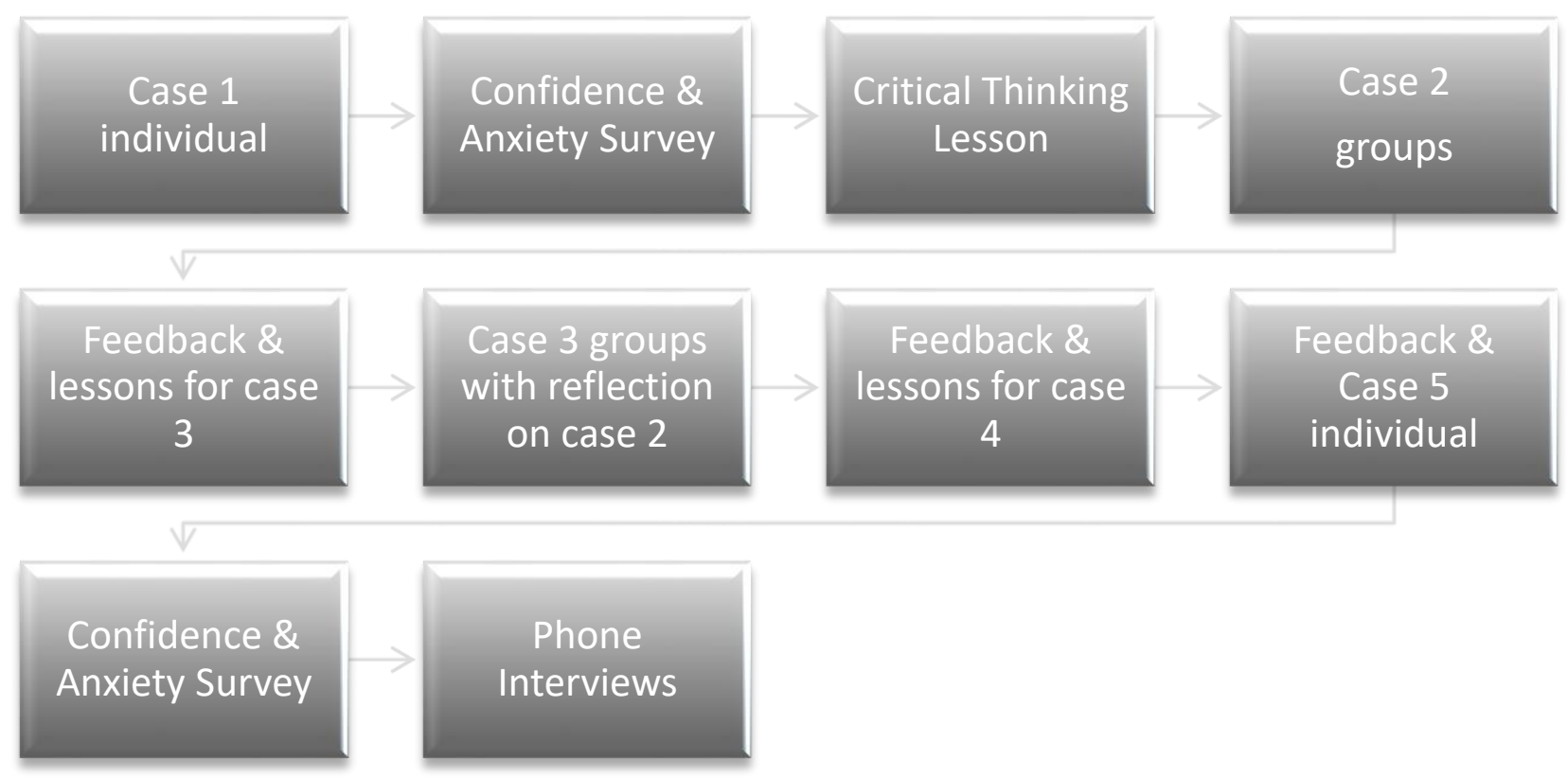

Figure 1. Teaching process. 
and goals. The second and third intervention case studies started with answering several questions to encourage reflection on what was learned on the previous case study. The group members for each case study were varied to allow each group member to contribute feedback from the instructor and what they learned from the last case study. Each case study also had a reduction in the amount of questions asked, providing less guidance as the semester progressed. The case studies were completed in class and the instructor was there to provide facilitation as needed for each group. The pre- and post-intervention case studies were completed individually. Students did not have access to feedback on the pre-intervention case study other than their grade prior to completion of post-intervention case study.

For all case studies, a second faculty member not connected with the class was asked to grade a sample of case studies to eliminate grading bias in the primary investigator. The goal was $80 \%$ or higher consistency between graders. If on first grading that benchmark was not met, the graders reviewed differences and grading sheet to determine discrepancies and then case studies were re-graded. All grading met the $80 \%$ threshold using this system. After students received feedback on the final postintervention case study, they were asked again to complete the confidence and anxiety survey.

A phone interview with volunteers was completed at the end of the students' first Level II fieldwork. An invitation was sent out one month and two weeks prior to the interviews to ask for volunteers from students who granted consent and would finish their first Level II fieldwork by the interview week. The interviews were conducted by a faculty member not connected with the class in which the case studies were completed. The interviews lasted from 20-30 minutes each. The semi-structured format of the questions provided opportunities for students to discuss their perspectives on the format and utility of the case studies for developing critical thinking when in their fieldwork settings.

\section{Data Analysis}

Quantitative. The quantitative data consisted of rubric scores for the case studies and the results of the confidence and anxiety survey. Paired t-tests were used to analyze rubric scores on the pre- and post-intervention case studies and scores on the pre- and post-confidence and anxiety levels.

Qualitative. The phone interviews were recorded with permission and transcribed. Qualitative content analysis (Schreier, 2012) was completed on the phone interview transcripts to explore student perceptions about carryover of critical thinking skills into the fieldwork experience and how the students felt the lesson design helped or hindered their use of critical thinking skills during fieldwork. The second author and a research assistant conducted the content analysis.

Analysis followed the three stages of open coding identified as conceptualizing, defining, and developing the information (Schreier, 2012). The conceptualizing stage focused on listing words and phrases that captured basic ideas and concepts from the 
data. Concepts that came up frequently were examined for similarities and differences, to gain different perspectives on their potential meaning. In the next stage, defining, similar concepts were grouped together and examined further to determine distinctions between them (how each was defined). In the final stage, developing categories, concepts from the previous stage were reviewed and discussed to determine potential main categories. Concepts were then further refined through discussion and placed into the final main categories and subcategories.

\section{RESULTS}

\section{Quantitative}

Thirty-one out of 32 students completed all the case studies and both surveys. To determine any change in critical thinking skills, anxiety, and confidence, quantitative analysis was completed. After normal distribution of the data was determined, a paired samples t-test was used to analyze pre- and post-case studies, anxiety, and confidence. All three areas showed a statistically significant change indicating improvement in critical thinking and confidence, while a reduction in anxiety was noted (Table 2). The pre-test case study $(M=-20.13, S D=3.68)$ and post-test case study $(M=31.45, S D=$ $2.20)$, as measured by the critical thinking rubric, was highly significant $(p<0.001)$. Confidence as measured by the survey at the start and end of the semester also showed a highly significant increase $(p<0.001)$ : pre-confidence $(M=106.35, S D=$ 13.89) compared to post-confidence $(M=122.38, S D=17.22)$. Anxiety showed a highly significant decrease from the start to the end of the semester $(p<0.001)$ : pre-anxiety $(\mathrm{M}$ $=65.87, \mathrm{SD}=10.78)$ and post-anxiety $(\mathrm{M}=57.96, \mathrm{SD}=12.18)$. The three dimensions of the confidence and anxiety scale including (a) using resources to gather information and listen fully, (b) using information to see the big picture, and (c) knowing and acting (White, 2011) all showed significant changes, $p<0.001$ from the start to end of the semester.

Table 2

Quantitative Analysis

\begin{tabular}{lccc}
\hline Rubric Scores & Mean & Standard deviation & $\underline{p}$ \\
$\quad$ Pre & 20.13 & 3.68 & $<0.001$ \\
Post & 31.45 & 2.20 & \\
& & & \\
Confidence & & 13.89 & $<0.001$ \\
$\quad$ Pre & 106.35 & 17.22 & \\
Post & 122.38 & & \\
Anxiety & & 10.78 & $<0.001$ \\
Pre & 65.87 & 12.18 & \\
Post & 57.96 & & \\
\hline
\end{tabular}




\section{Qualitative}

Responses were gathered from five students whose fieldwork placements consisted of adult settings of acute care, outpatient, and in-patient rehabilitation. No students with pediatric placements volunteered for the focus group. Categories that emerged through the qualitative content analysis from the phone interviews focused on students' perspectives on what they learned from the case studies, their experience of confidence and anxiety, and the ways in which they applied critical thinking skills from the case studies to Level II experiences. A summary with direct quotes is provided in Table 3.

Case studies. Students reported that the case studies enabled them to connect academic information with real-world experience on their Level II fieldwork and clarify their expectations of clinical practice. They found that problem-solving skills developed through the cases were relevant to clinical practice and helped them develop a logical thinking process. Students also reported that the progression from simpler to more complex cases helped to facilitate their learning.

Confidence and anxiety. Students reported their confidence and anxiety levels differently at the beginning and end of the semester. In the beginning of the semester, low grades were seen as negative, making students question their knowledge and feel anxious about their preparation for practice. At the end of semester, students reported that the overall experience of working through the clinical problems posed by the case studies helped them improve their confidence and reduce their anxiety.

Application of skills. Students reported that all aspects of critical thinking discussed in class were important for Level II fieldwork. They emphasized the importance of being able sort through different sources of information, including the initial diagnosis and observations of the client, to determine other issues affecting performance. Students also highlighted the ability to develop holistic approaches, tailor intervention to individual clients, and provide evidence to support their clinical reasoning.

Table 3

Qualitative Analysis with Direct Quotes from Participants

\begin{tabular}{|c|c|}
\hline Case Studies & \\
\hline $\begin{array}{l}\text { Connection with } \\
\text { real-world } \\
\text { experiences }\end{array}$ & $\begin{array}{l}\text { - I was able to ... connect the academic part and bring that } \\
\text { together with actual real-life experience working with patients. }\end{array}$ \\
\hline $\begin{array}{l}\text { Developing logical } \\
\text { thinking process }\end{array}$ & $\begin{array}{l}\text { - It helped to almost overdo the clinical reasoning .... to break } \\
\text { down everything ... a and overanalyze every little piece of it. }\end{array}$ \\
\hline $\begin{array}{l}\text { Set expectations for } \\
\text { clinical practice }\end{array}$ & $\begin{array}{l}\text { - I think it definitely helped-got exposed to a lot of different types } \\
\text { of cases ... it helped you prepare for when you're out in the } \\
\text { clinic- especially when it comes to evals. }\end{array}$ \\
\hline $\begin{array}{l}\text { Increasing difficulty } \\
\text { helped learning }\end{array}$ & $\begin{array}{l}\text { - [The instructor] held our hand at the beginning and we all got } \\
\text { horrible grades and the more she let our hands go and the more }\end{array}$ \\
\hline
\end{tabular}


we thought clinically and critically for ourselves the better we did and by the last one we felt adequately prepared to work through a whole case study by ourselves.

\section{Confidence and Anxiety}

Experience

improved confidence

Experience lowered anxiety

Grade effect on selfperception of knowledge
- I think going into fieldwork it [case study work] may have increased my confidence, just from breaking down those tasks.

- It was good to go through those scenarios and think what I was going to do if I was actually presented with a patient in that scenario.

Application

Drawing conclusions

Thinking holistically

Tailor interventions

Finding evidence
- When you get the bad grade you're like, oh man I don't know anything, and then when you know your kind of, uh, you're cued to give more information, you realize you do know more than what you initially put.
- Thinking outside the box, kinda um, like what to do from here, if that makes sense, so in the case studies, when you pick out an evaluation you got the results and from there and especially in the real world, so these are my results, so should I do this evaluation or no?

- I had several patients that speak well, look like no cognitive deficits but l've learned over time that it's always good to kind of do a screen, and make sure there isn't cognitive deficits . . . you kind of realize, oh, actually this patient is missing a couple of things - like I may have not noticed that they are missing some visuospatial deficits during the screen, and when you do the assessment that actually shows up a little bit more.

- I had a pediatric patient that we had to change things around a little bit. .. we had to devise different games I could do for the child in order for him to do specific movements we were looking for in his therapy.

- I was allowed to research [the topic] and I said it could be this . . . I had to pull up multiple sources ... I was able to show her [fieldwork supervisor]. . . and she was like I am glad you showed me, I don't want you to say something just because you thought that is what it is, you have to prove it to me.

When comparing support for choices in case studies students demonstrated greater ability to provide stronger evidence for their choices as the semester progressed. Being able to defend choices is an important part of critical thinking (Brookfield, 2012). Several students on the phone interviews were able to share an instance when they had to search the evidence and defend their choices, which they reported they were comfortable doing. Examples of how defense of choices developed are provided in Table 4. 
Table 4

Defense of Choices

Early responses
Range of motion (ROM) \& manual muscle
test (MMT) done to "observe and quantify
weakness and ROM limitations"

The Box and Block assessment was chosen to "test gross manual dexterity and fine motor skills"

Later responses
"Assessing ROM will indicate if the client
is dropping items because of limited ROM
or because of weakness of the
extensors/flexors"

The 9-hole Peg Test was chosen- "the client reported difficulty participating in sewing ... assessing dexterity in addition to ROM ... will help indicate whether the difficulty is because of dexterity or limited ROM"

"Fluidotherapy for comfort and increasing blood flow" (with no citation)
"Release exercise because research shows that it can be helpful for relieving carpal tunnel symptoms by releasing the compression of the median nerve. It also has increased the pressure pain threshold in patients" (with journal article citation)

\section{Limitations}

There were several limitations to this study. A small convenience sample limits applicability to other settings ( 31 for the case studies and five for the phone interviews). Although the student grades improved with each case study, this may be partially due to a practice effect of receiving feedback on each case study that showed them where they did well or needed improvement. Students also engaged in other learning activities in concurrent classes that may have contributed to their learning and confidences, such as their third Level I fieldwork and engagement in a program development class.

The phone interviews were limited to five participants and did not represent all the Level II fieldwork placements; students in pediatric settings were most noticeably missing. Students who felt the class or the case studies were least helpful may have chosen not to volunteer, skewing the results.

\section{DISCUSSION}

Despite limitations in the study, the students' confidence levels as measured by the NASC-CDM ${ }^{\circledR}$ improved significantly by the end of the semester. All students reported the importance of critical thinking skills and the use of these skills on their fieldwork and feeling confident by the end of their fieldwork. One reason for the increase in grades was improvement in the students' ability to explain why they made particular choices on the case studies. 
A commonly discussed concern for class design from students was the grading of the case studies. Assessment of any kind can influence students in positive or negative ways (Vaessen et al., 2016). Negative outcomes can include reduced confidence and motivation to learn (Vaessen et al., 2016; Wesson \& Derrer-Rendall, 2011). Being over or under confident can affect academic achievement, especially if expectations of students is met with a lower than expected grade (Wesson \& Derrer-Rendall, 2011). Although the pre-test case study and the first intervention case studies were worth only five points, students expressed a strong relationship to their confidence and anxiety to start fieldwork with lower grades on individual assignments, despite a good overall grade. An example of feedback demonstrated this overall concern: "[With] the grading of the case studies . . . I wondered if I was actually understanding the material . . . I [thought] what was I going to do if I was actually presented with a patient in that scenario?" Although the lower grades overall seemed to help motivate the students on the next case study, many students expressed being discouraged by the process. This can relate to whether the student had self-confidence before the case studies and their expectations about achievement (Wesson \& Derrer-Rendall, 2011). It is important to create lesson designs that create a balance between providing honest feedback and grades with student perceptions and current skill level. By the end of the semester, student improvement was reflected in better grades, but they continued to express concern about grading even during the phone interviews. Students ability to achieve academically goes well beyond intellectual quotient (Martin, Rodrigo, Izquierdo, \& Ajenjo, 2017), and these factors need to be considered with lesson design. Finding a balance between grading that encourages deeper learning on future lessons without affecting confidence and motivation needs to be further considered in future research.

Case studies can be an important part of teaching critical thinking but need to be designed to be as realistic as possible and relate to the students' experiences (Thistlethwaite et al., 2012). Specifically, case studies must be carefully designed so that students understand the skills they are learning can be carried over to different diagnoses and clinical settings. The use of the videos and common diagnoses was seen as helpful, but students that completed their Level II fieldwork in acute care found the case studies less helpful. One student saw primarily stroke clients in acute care and felt that the case studies had limited applicability to his first Level II fieldwork, because the case studies were all in an outpatient setting, despite one of them being a stroke case. No students who completed a pediatric placement responded to the request for phone interviews, possibly in part because they did not see the case studies as helpful for their fieldwork experience. Varying the settings and possibly including a pediatric case study may have helped the students relate the case studies more directly to their fieldwork, but students need to understand the transferability of skills between settings and client types. Although active learning can help students better connect classroom learning to real world situations (Singh, 2017), being more explicit in the classroom of these connections may help students bridge more information to the clinical setting (Kalyuga, 2013). For example, comparing how the process of assessing and establishing a treatment plan for a new client is similar across settings would be a helpful addition to class feedback and discussion. 
Although the academic program at the university where the research was completed had critical thinking components threaded throughout the curriculum, being more explicit when different aspects of critical thinking are being addressed and creating a more formal progression of critical thinking skills would be beneficial (Kalyuga, 2013). While there was a progression of increasing difficulty with each case study, starting this progression in the first semester and then building on that each semester would help students integrate different concepts of critical thinking. This may allow students to draw on and relate their learning more to their clinical experiences.

\section{CONCLUSION}

This study provided further support for the use of case studies to promote critical thinking and helps inform the use of case studies and lesson design when addressing critical thinking. Research should continue to explore the efficacy of case studies to address critical thinking, due to continued mixed results in the literature. Mixed results on the use of case studies for critical thinking may result when other important factors beyond the case studies are not considered. These factors include lesson design, level of facilitation, explicitness of connecting lessons to practice, and student perceptions of their capabilities. Lesson design is an important part of creating a learning atmosphere that promotes learning and increases confidence with applying skills. Lesson design including format, grading, and explicit connections of lessons and objectives have been discussed in the literature and been suggested as important considerations through this study. Student facilitation should also include strongly connecting the skills and learning to their clinical settings to help carryover of skills. Although this study explicitly stated the goals of each case study was critical thinking, future research should include looking at how class materials and activities are not only connected to course objectives, but to clinical expectations. Emotional response to lessons can play a strong role in the students' abilities to incorporate these skills in practice. Confidence and anxiety level of students influence success in the classroom and should continue to be explored in research to help better inform classroom design and development of skills such as critical thinking.

\section{References}

American Occupational Therapy Association. (2015a). Academic Programs Annual Data Report: Academic year 2014-2015. Retrieved from https://www. aota. org/ /media/Corporate/Files/EducationCareers/Educators/2014-2015-AnnualData-Report. pdf

American Occupational Therapy Association. (2015b). Standards for continuing competence. American Journal of Occupational Therapy, 69(Suppl. 3), 6913410055p1-6913410055p3. https://doi.org/10.5014/ajot.2015696S16

American Occupational Therapy Association. (2017). Vision 2025. American Journal of Occupational Therapy, 71, 7103420010. https://doi.org/10.5014/ajot.2017.713002

Arsel, Z. (2017). Asking questions with reflexive focus: A tutorial on designing and conducting interviews. Journal of Consumer Research, 44(4), 939-948. https://doi.org/10.1093/jcr/ucx096 
Berkhout, J. J., Helmich, E., Teunissen, P. W., van den Berg, J. W., van der Vleuten, C. P. M., \& Jaarsma, A. D. C. (2015). Exploring the factors influencing clinical student's self-regulated learning. Medical Education, 49(6), 589-600. https://doi.org/10.1111/medu.12671

Bhoyrub, J., Hurley, J., Neilson, G. R., Ramsay, M., \& Smith, M. (2010). Heutagogy: An alternative practice based learning approach. Nurse Education in Practice, 10, 322-326. https://doi.org/10.1016/..nepr.2010.05.001

Blaschke, L. M. (2012). Heutagogy and lifelong learning: A review of heutagogical practice and self-determined learning. International Review of Research in Open and Distance Learning, 13(1), 56-71. https://doi.org/10.19173/irrodl.v13i1.1076

Brookfield, S. D. (2012). Teaching for critical thinking: Tools and techniques to help students question their assumptions. San Francisco, CA: Jossey-Bass.

Brudvig, T. J., Dirkes, A., Dutta, P., \& Rane, K. (2013). Critical thinking skills in health care professional students: A systematic review. Journal of Physical Therapy Education, 27(3), 12-25. https://doi.org/10.1097/00001416-201307000-00004

Cattaneo, K. H. (2017). Telling active learning pedagogies apart: from theory to practice. Journal of New Approaches in Educational Research, 6(2), 144-152. https://doi.org/10.7821/near.2017.7.237

Chung, J. C. C. (2001). Active learning of geriatric rehabilitation: Deliberations of an undergraduate occupational therapy programme. Scandinavian Journal of Caring Sciences, 15, 250-256. https://doi.org/10.1046/j.1471-6712.2001.00033.x

Elder, L., \& Paul, R. (2009). Guide to critical thinking. Tomales, CA: Foundation for Critical Thinking.

Foundation for Critical Thinking. (2017). Critical thinking: Where we begin. Retrieved from http://www.criticalthinking.org/pages/critical-thinking-where-to-begin/796

Friedlander, M. J., Andrews, L., Armstrong, E. G., Aschenbrenner, C., Kass, J. S., Ogden, P., . . \& Viggiano, T. R. (2011). What can medical education learn from the neurobiology of learning? Academic Medicine, 86(4), 415-420. https://doi.org/10.1097/ACM. 0b013e31820dc197

Fry, M., \& MacGregor, C. (2014). Confidence and impact on clinical decision-making and behavior in the emergency department. Australian Emergency Nursing Journal, 17, 91-97. https://doi.org/10.1016/j.aenj.2014.03.003

Goldbach, W. P., \& Stella, T. C. (2017). Experiential learning to advance student readiness for Level II fieldwork. Journal of Occupational Therapy Education, 1 (1). https://doi.org/10.26681/jote.2017.010103

Goswami, U. (2008). Principles of learning, implications for teaching: A cognitive neuroscience perspective. Journal of Philosophy of Education, 42(3-4).

Hasim, S. B. M., Yasin, R. B. M., \& Rosli, R. B. (2015). A meta-analysis study on the effectiveness of higher order thinking skills (HOTS) based learning in science and mathematics subjects. Proceeding: $7^{\text {th }}$ International Seminar on Regional Education, 3(3), 1334-1349.

Heft, H. E., \& Scharff, L. F. V. (2017). Aligning best practices to develop targeted critical thinking skills and habits. Journal of the Scholarship of Teaching and Learning, 17(3), 48-67. https://doi.org/10.144434/josotl.v17i3.22600

Henderson, W., Coppard, B., \& Qi, Y. (2017). Identifying instructional methods for development of clinical reasoning in entry-level occupational therapy education: 
A mixed methods design. Journal of Occupational Therapy Education, 1(2). https://doi.org/10.26681/jote.2017.010201

Hildenbrand, K. J., \& Schultz, J. A. (2012). Development of a rubric to improve critical thinking. Athletic Training Education Journal, 7(3), 86-94. https://doi.org/10.5608/070386

Hofsten, A., Gustafsson, C., \& Häggström, E. (2010). Case seminars open doors to deeper understanding- Nursing students' experiences of learning. Nurse Education Today, 30, 533-538. https://doi.org/10.1016/j.nedt.2009.11.001

Holmes, W. M., \& Scaffa, M. E. (2009). An exploratory study of competencies for emerging practice in occupational therapy. Journal of Allied Health, 38(2), 81-90.

Hong, S., \& Yu, P. (2017). Comparison of the effectiveness of two styles of case-based learning implemented in lectures for developing nursing students' critical thinking ability: A randomized controlled trial. International Journal of Nursing Studies, 68, 16-24. https://doi.org/10.1016/i.jinurstu.2016.12.008

Jaffe, L., Gibson, R., \& D’Amico, M. (2015). Process-oriented guided-inquiry learning: A natural fit for occupational therapy education. Occupational Therapy in Health Care, 29(2), 115-125. https://doi.org/10.3109/07380577.2015.1010030

Kaddoura, M. A. (2011). Critical thinking skills of nursing students in lecture-based teaching and case-based learning. International Journal for the Scholarship of Teaching, 5(2), 1-18. https://doi.org/10.20429/ijsotl.2011.050220

Kalyuga, S. (2013). Enhancing transfer by learning generalized domain knowledge structures. European Journal of Psychology of Education, 28(4), 1477-1493. https://doi.org/10.1007/s10212-013-0176-3

Khan, M. A., Qamar, K., Khalid, S. Javed, H., Malik, M., Gondal, A., ...\& Imtiaz, F. (2015). Comparison of case based learning with conventional teaching-student's perspective. Pak Armed Forces Medical Journal, 65(3), 415-419.

Kirschner, P. A., Sweller, J., \& Clark, R. E. (2006). Why minimal guidance during instruction does not work: An analysis of the failure of constructivist, discovery, problem-based, experiential, and inquiry-based teaching. Educational Psychologist, 41(2), 75-86. https://doi.org/10.1207/s15326985ep4102 1

Lederer, J. M. (2007). Disposition toward critical thinking among occupational therapy students. American Journal of Occupational Therapy, 61(5), 519-526. https://doi.org/10.5014/ajot.61.5.519

Martin, N. S., Rodrigo, G. I., Izquierdo, C. G., \& Ajenjo, P. P. (2017). Exploring academic performance: Looking beyond numerical grades. Universal Journal of Educational Research, 5(7), 1105-1112. https://doi.org/10.13189/ujer.2017.050703

Mitchell, A. W., \& Xu, Y. J. (2011). Critical reasoning scores of entering bachelor's and master's students in an occupational therapy program. American Journal of Occupational Therapy, 65, e86-e94. https://doi.org/10.5014/ajot2011.001511

Moffett, N., \& Fleischer, S. C. (2013). Matching the neurobiology of learning to teaching principles. Journal on Excellence in College Teaching, 24(3), 121-151.

Murdoch-Eaton, D., \& Whittle, S. (2012). Generic skills in medical education: Developing the tools for successful lifelong learning. Medical Education, 46, 120128. https://doi.org/10.1111/j.1365-2923.2011.04065.x 
Neistadt, M. E. (1996). Teaching strategies for the development of clinical reasoning. American Journal of Occupational Therapy, 50(8), 676-684. https://doi.org/10.5014/ajot.50.8.676

Ornstein, A. C., \& Hunkins, F. P. (2013). Curriculum: Foundations, principles, and issues ( $6^{\text {th }}$ ed.). Boston: Pearson.

Otting, H., Zwaal, W., Tempelaar, D., \& Gijselaers, W. (2010). The structural relationship between students' epistemological beliefs and conceptions of teaching and learning. Studies in Higher Education, 35(7), 741-760. https://doi.org/10.1080/03075070903383203

Qi, M., Yi, Q., Mo, M. Huang, H., \& Yang, Y. (2018). Application of case-based learning in instructing clinical skills on nursing undergraduates. Biomedical Research, 29(2), 300-304. https://doi.org/10.4066/biomedicalresearch.29-17-2377

Raidal, S. L., \& Volet, S. E. (2009). Preclinical students' predispositions towards social forms of instruction and self-directed learning: A challenge for the development of autonomous and collaborative learners. Higher Education, 57, 577-596. https://doi.org/10.1007/s10734-008-9136-z

Reed, H. E. (2014). An examination of critical thinking skills in traditional and simulated environments for occupational therapy students [Doctoral Dissertation]. Retrieved from file:///E:/CT\%20CBL/An Examination of Critical Thi.pdf

Salbach, N. M., \& Jaglal, S. B. (2010). Creation and validation of the evidence-based practice confidence scale for health care professionals. Journal of Evaluation in Clinical Practice, 17, 794-800. https://doi.org/10.1111/j.1365-2753.2010.01478.x

Savery, J. R. (2006). Overview of problem-based learning: Definitions and distinctions. Interdisciplinary Journal of Problem-Based Learning, 1(1), 9-20. https://doi.org/10.7771/1541-5015.1002

Schunk, D. H. (2012). Learning theories: An educational perspective (6 $6^{\text {th }}$ ed.). Boston: Pearson.

Schreier, M. (2012). Qualitative content analysis in practice. Thousand Oaks, CA: Sage. Silen, C., \& Uhlin, L. (2008). Self-directed learning- A learning issue for students and faculty! Teaching in Higher Education, 13(4), 461-475. https://doi.org/10.1080/13562510802169756

Singh, J. (2017). Enhancing student success in health care programs: Active learning in a hybrid format. Journal of Instructional Pedagogies, 18, 1-14.

Suliman, W. A., \& Halabi, J. (2007). Critical thinking, self-esteem, and state of anxiety of nursing students. Nurse Education Today, 27, 162-168. https://doi.org/10.1016/i.nedt.2006.04.008

Sze-yeng, F., \& Hussain, R. M. R. (2010). Self-directed learning in a socioconstructivist learning environment. Procedia Social and Behavioral Sciences, 9, 1913-1917. https://doi.org/10.1016/j.sbspro.2010.12.423

Taylor, E. W. (2008). Transformative learning theory. New Directions for Adult Continuing Education, 119, 5-15. https://doi.org/10.1002/ace.301

Thistlethwaite, J. E., Davies, D., Ekeocha, S., Kidd, J. M., MacDougall, C., Matthews, P., . . \& Clay, D. (2012). The effectiveness of case-based learning in health professional education. A BEME systematic review: BEME guide no. 23. Medical Teacher, 34(6), e421-e444. https://doi.org/10.3109/0142159X.2012.680939 
Thomas, A., Saroyan, A., \& Dauphinee, W. D. (2011). Evidence-based practice: A review of theoretical assumptions and effectiveness of teaching and assessment interventions in health professions. Advances in Health Science Education, 16, 253-276. https://doi.org/10.1007/s10459-010-9251-6

Vanessen, B. E., van den Beemt, A., van de Watering, G., van Meeuwen, L. W., Lemmens, L., \& den Brok, P. (2016). Student's perception of frequent assessments and its relation to motivation and grades in a statistics course: A pilot study. Journal of Assessment \& Evaluation in Higher Education, 42(6), 872886. https://doi.org/10.1080/02602938.2016.1204532

Velde, B. P., Wittman, P. P., \& Vos, P. (2006). Development of critical thinking in occupational therapy students. Occupational Therapy International, 13(1), 49-60. https://doi.org/10.1002/oti

Vogel, K. A., Geelhoed, M., Grice, K. O., \& Murphy, D. (2009). Do occupational therapy and physical therapy curricula teach critical thinking skills? Journal of Allied Health, 38(3), 152-157.

Wesson, C. J., \& Derrer-Rendall, N. M. (2011). Self-beliefs and student goal achievement. Psychology Teaching Review, 17(1), 3-12.

White, K. A. (2011). The development and validation of a tool to measure selfconfidence and anxiety in nursing students while making clinical decisions (Doctoral dissertation). Retrieved from ProQuest Dissertation Publishing.

White, K. A. (2013). Development and validation of a tool to measure self-confidence and anxiety in nursing students during clinical decision making. Journal of Nursing Education, 52(X), 1-9. https://doi.org/10.3928/01484834-20131118-05 